\title{
Potential of process information transfer along the process chain of hybrid components for process monitoring of the cutting process
}

\author{
Berend Denkena $^{1} \cdot$ Bernd-Arno Behrens $^{2} \cdot$ Benjamin Bergmann ${ }^{1} \cdot$ Malte Stonis $^{2} \cdot$ Jens Kruse $^{2} \cdot$ Matthias Witt $^{1}$
}

Received: 24 July 2020 / Accepted: 19 January 2021 / Published online: 19 February 2021

(c) The Author(s) 2021

\begin{abstract}
The production of hybrid components involves a long process chain, which leads to high investment costs even before machining. To increase process safety and process quality during finishing, it is necessary to provide information about the semi-finished parts geometry for the machining process and to identify defect components at an early stage. This paper presents an investigation to predict variations in dimension and cavities inside the material during cross-wedge rolling of shafts based on measured tool pressure. First, the process is investigated with respect to the variation in diameter for three roll gaps and two materials. Subsequently, features are generated from the hydraulic pressures of the tools and multi-linear regression models are developed in order to determine the resulting diameters of the shaft shoulder. These models show better prediction accuracy than models based on meta-data about set roll gap and formed material. The features are additionally used to successfully monitor the process with regard to the Mannesmann effect. Finally, a sensor concept for a new crosswedge rolling machine to improve the prediction of the workpiece geometry and a new approach for monitoring machining processes of workpieces with dimensional variations are presented for upcoming studies.
\end{abstract}

Keywords Cross-wedge rolling $\cdot$ Process monitoring $\cdot$ Process chain $\cdot$ Machining

\section{Introduction}

The mass reduction of components is one of the most effective methods of reducing $\mathrm{CO}_{2}$ emissions and thus fuel consumption in the mobility sector [1]. An approach to reduce the weight of highly stressed components involves the combination of different materials in composite parts, known as hybrid components. This allows components to be adapted to the local load by using the most qualified material. This is the focus of the Collaborative Research Center (CRC) 1153, which is researching a new process chain called Tailored Forming. In contrast to current manufacturing and production processes for hybrid solid components, the materials are joined before forming and the subsequent machining. The simple geometry of the semi-finished parts facilitates the handling as well as the reliable production of

Matthias Witt

witt@ifw.uni-hannover.de

1 Institute of Production Engineering and Machine Tools, Leibniz Universität Hannover, Garbsen, Germany

2 IPH-Institut Für Integrierte Produktion Hannover gGmbH, Hannover, Germany a material-closed joining zone compared to existing production methods. The new process chain will increase the availability of hybrid workpieces with a load-specific material gradation.

One of the investigated forming processes is cross-wedge rolling (CWR). CWR is a highly efficient forming process and particularly suitable as a preform operation for subsequent forging processes [2]. This forming process is faced with new challenges with regard to Tailored Forming, due to the combination of different materials which have to be heated, formed and heat treated at different temperatures [3, 4]. This requires a profound understanding of the process compared to the production of mono material components. The consequence of insufficient process parameters during the CWR process can be defects on the surface of the rolled part or even within the rolled part $[5,6]$. Internal material defects, the so-called Mannesmann effect, are investigated since the end of the nineteenth century and is still the subject of current research [5, 7-13]. A detailed understanding of forces and strains occurring within the workpiece during CWR helps to avoid an accidental Mannesmann effect. Parameters that influence the Mannesmann effect and lead to voids inside the part are, for example, the forming speed, the 
geometry of the forming tool and the workpiece temperature. The interaction of these parameters results in stress conditions in the workpiece, which cause internal defects.

For CWR, several approaches to avoid defective workpieces were already researched. Traxler and Baghbanpourasl [14] investigated the stability of a CWR process with help of thermal imaging, to gain information about the temperature distribution and the quality of the parts rolled. Pater analysed the measured drive force of the CWR device compared to simulation results and the calculated forming forces to validate the simulation model [5]. Tomczak et al. investigated numerically and experimentally the forming of spheres manufactured by CWR. In the experiments, the process was investigated with respect to potential failure modes by investigating forces and strains [15]. Pater et al. investigated the critical tool length at which internal cracking occurred during CWR of C45. The process was analysed by simulation and verified by experimental investigations. A temperature, tool length and damage dependent model was created to iteratively calculate the optimal tool length to avoid internal cracking [16].

If internal defects occur during CWR, they cause a significant reduction in the service life of the manufactured components. Especially, if different material combinations with inhomogeneous temperature distribution are formed and production variations of previous joining processes have to be taken into account, monitoring of the workpiece quality is necessary. The defect workpieces should be removed from the process chain before the end-of-line measurement to save resources and production capacities. However, signal-based monitoring for the Mannesmann effect has not yet been implemented during the process. In other forming processes, such monitoring of process anomalies is already state-of-the-art $[17,18]$. In CWR, end-of-line quality control is usually used. However, internal defects cannot be detected by an external visual inspection after rolling. For the identification of these defects, ultrasonic partial tests or X-rays are used. But these technologies have a high acquisition cost and reach their limits in the context of series production monitoring with regard to the inspection duration.

After forming, a machining process is required to finish the workpiece geometry. Hybrid workpieces present new challenges in terms of process safety during machining. In process monitoring, signals with a high correlation to the process force are primarily used $[19,20]$. If the process is subject to larger fluctuations, the sensitivity of envelope based monitoring approaches is reduced due to the increased signal variance. Commercial process monitoring systems often use force-sensitive drive currents of the machine control and are therefore significantly influenced by the fluctuations [21, 22]. Denkena et al. [23] have already shown that the material-dependent gradient of the process force during the machining of hybrid workpieces leads to challenges within the process monitoring. This also applies to the geometry variation of the formed part. New methods have to be researched to provide a safe machining process for hybrid parts. One approach followed within the CRC 1153 is the fusion of process information from previous manufacturing steps with process signals measured during the machining process to improve process monitoring with respect to robustness and sensitivity. Based on the process data of the previous production steps, it is possible to predict, for example, the geometry of the semi-finished part before machining. Using this information, the influences of the variation of the geometry can be reduced during process monitoring and defective components can be removed.

This paper focuses on the signal-based prediction of workpiece quality of CWR components to provide additional information for the machining process. For this purpose, two materials are formed with three different roll gaps. First, the resulting geometry variations are determined and the thermal run-in and mechanical setting behaviour is analysed. Features are then generated from the measured hydraulic pressures, which are directly in correlation with the forming forces. These as well as the meta-data about set roll gap and selected material are used to investigate a model-based prediction of the workpiece geometry. Subsequently, the potential of the generated features with regard to monitoring defective components is investigated. Finally, a new CWR machine, which is currently under construction, is presented to enable the investigation of the CWR process with more accurate measurements of process information and data logging.

The presented work with mono material workpieces is part of the fundament, built for future research on hybrid workpieces within the subprojects B1 and B5 of the CRC 1153 regarding process monitoring of hybrid manufacturing chains and their production steps. Based on the process signals of the previous manufacturing steps, process information will be generated for each workpiece and provided as additional parameters for the monitoring of machining. Figure 1 shows a process chain developed for the CRC 1153. With this additional knowledge, the monitoring can be individually adapted to the workpiece to achieve higher process safety.

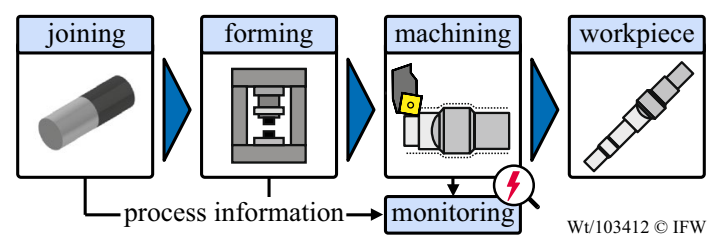

Fig. 1 Tailored Forming process chain with monitoring of the machining process supported by historical data of the workpiece 


\section{Test setup}

For the experimental investigations, a self-build test rig at the Institut für Integrierte Produktion gGmbH (IPH) was used. The test stand uses two hydraulic cylinders to create the tool movement during rolling. The vertical force resulting from the forming process is compensated by a hydraulic press, in which the test rig, further on called CWR-module, is mounted. The tool and the nominal dimensions of the finished workpiece for a roll gap width of $30 \mathrm{~mm}$ are depicted in Fig. 2.

The CWR-module can mount tools up to a length of $1500 \mathrm{~mm}$ with a width of $500 \mathrm{~mm}$. The surface geometry of the tools is equipped with forming wedges, which induce the axial material flow of the forming process [5]. The maximum force of each sled that mounts the tools is $125 \mathrm{kN}$ in horizontal direction. The maximum vertical force is theoretically only limited by the capability of the hydraulic press. The vertical distance between the tools is called the roll gap width and is realized by mechanical stops between the press table and press ram. It can be adjusted with different spacers in segments as low as 1/10th of a millimetre.

The cross-wedge rolling tools themselves are mounted onto aluminium plates that contain holes into which heating cartridges can be inserted. The tools can be heated to more than $250{ }^{\circ} \mathrm{C}$, depending on the cartridges used. Between the baseplate of the CWR-module's sled and the aluminium plates, thermal insulation is placed, depicted in Fig. 3. This AS $600 \mathrm{M}$ polymer insulation $(<0.3 \mathrm{~W} / \mathrm{m} \mathrm{K})$ ensures optimal heating of the tools. The movement of the tools is logged with one ultrasonic sensor for each sled. The sensors used (UGT513 made by ifm) are recorded by a Beckhoff system with a sampling frequency of $100 \mathrm{~Hz}$. The maximum measuring range is $2 \mathrm{~m}$ at a measuring resolution of $3 \mathrm{~mm}$. This is accurate enough for the purpose of position monitoring. The hydraulic force of the module sleds is calculated from the hydraulic pressure measured at each of the two cylinders mounted to the sleds.

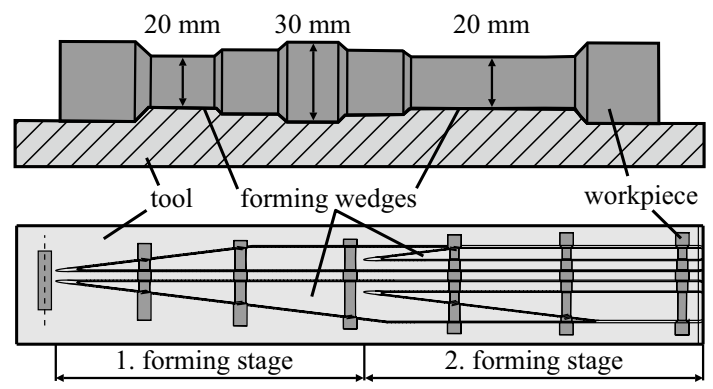

Fig. 2 Illustration of the tool and the nominal workpiece geometry for a roll gap of $30 \mathrm{~mm}$

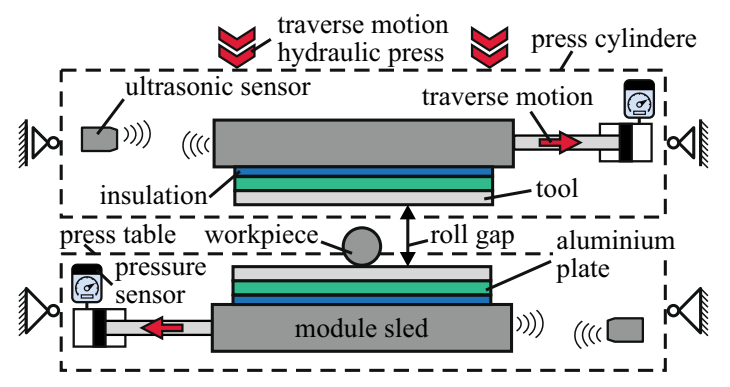

Fig. 3 Schematic drawing of the CWR-module at IPH

The workpieces used for the experimental investigations are made of $\mathrm{C} 22.8$ and $41 \mathrm{Cr} 4$, which material properties are shown in Table 1. C22.8 is considered unalloyed structural steel for parts in general mechanical engineering and vehicle construction. The quenched and tempered steel $41 \mathrm{Cr} 4$ is a versatile material and is mainly used in automotive and vehicle construction. It is considered difficult to join but can be welded via friction or plasma transferred arc welding to create hybrid workpieces [24]. The dimension of all workpieces was $150 \mathrm{~mm}$ in length, $30 \mathrm{~mm}$ in diameter. Before rolling, the parts were heated with an induction heating device for $60 \mathrm{~s}$ up to a temperature of $1250{ }^{\circ} \mathrm{C}$. After heating, the parts were manually transferred into the CWRmodule and aligned with a mechanical positioning aid. After the part was positioned correctly, the ram of the hydraulic press was lowered, closing the module to the pre-set roll gap width. Next, the valve for the hydraulic pressure for the tool cylinders is opened by the automation system and the sleds are moved for about $11 \mathrm{~s}$. After the rolling process, the press ram is lifted, and the rolled part can be removed from the CWR-module.

This was done for three different roll gap widths (28, $29,30 \mathrm{~mm}$ ) with the two different materials with at least five workpieces per combination. In addition, the various parameter combinations consisting of material and roll gap width were carried out in an experimental design presented in Table 2. The shafts were manufactured one after the other in a continuous process in order 1-30. The selected design

Table 1 Material properties

\begin{tabular}{lll}
\hline Material properties & \multicolumn{2}{l}{ Materials } \\
\cline { 2 - 3 } & $\mathrm{C} 22.8$ & $41 \mathrm{Cr} 4$ \\
\hline Density in $\mathrm{g} / \mathrm{cm}^{3}$ & 7.85 & 7.72 \\
Hardness in $\mathrm{HV}$ & 168 & 255 \\
Ultimate tensile strength in $\mathrm{MPa}$ & $410-540$ & $800-1200$ \\
Young's modulus in GPa & 210 & 210 \\
Thermal expansion coefficient in $10^{-6} \mathrm{~K}^{-1}$ & 12.1 & 11.1 \\
Thermal conductivity in W/mK & 57 & 42
\end{tabular}


Table 2 Overview experimental design

\begin{tabular}{llc}
\hline Workpiece $\mathrm{nr}$ & Roll gap in $\mathrm{mm}$ & Material \\
\hline $1,2,3,29,30$ & 30 & $41 \mathrm{Cr} 4$ \\
$7,8,9,25,26$ & 29 & \\
$13,14,15,16,17$ & 28 & $\mathrm{C} 22.8$ \\
$4,5,6,27,28$ & 30 & \\
$10,11,12,23,24$ & 29 & \\
$18,19,20,21,22$ & 28 & \\
\hline
\end{tabular}

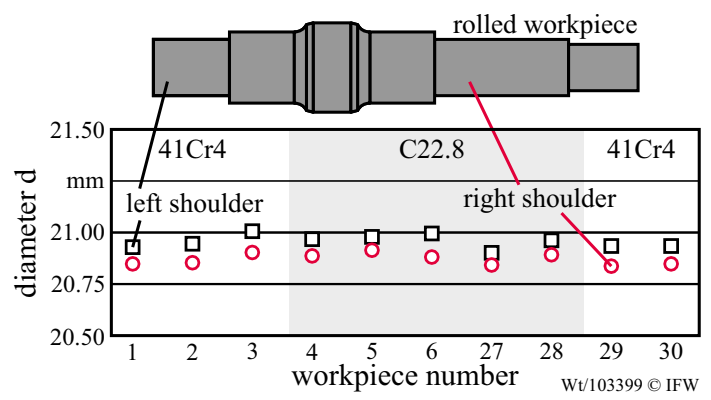

Fig. 4 Mean shaft diameter of the left and right shoulder at a roll gap of $30 \mathrm{~mm}$ for cross-wedge rolled shafts of C22.8 and $41 \mathrm{Cr} 4$

offers the possibility to investigate the process with regard to thermal run-in and mechanical setting behaviour.

\section{Investigation of the manufacturing variations}

In the first step, the influence of three effects was investigated, which possibly result in disturbance variables for the measurements. For this purpose, the thermal run-in behaviour, the mechanical setting behaviour after changing the production setup and the influence of the different material properties on the workpiece geometry were analysed. After the components had been manufactured and cooled down, the different diameters of the component were measured at three positions around the circumference for three shoulders by using a micrometre screw. The average value was determined from these three measurements.

Based on the results of the diameter variations, an investigation was carried out to determine, if machine run-in behaviour could be detected during the production of components by CWR. The heat introduced into the tools and the machine by the parts of the workpiece can cause this over time behaviour. This can lead to deviations in tool spacings and machine tolerances. Figure 4 shows the average diameters for the left and right shaft shoulder for different workpieces. The results are discussed as an example using the components manufactured with a roll gap of $30 \mathrm{~mm}$.
Comparing the diameters of the left and right shoulder of the first three workpieces (number 1-3) with those of shaft number 29 and number 30, no fluctuations can be detected which indicates a thermal run-in behaviour of the system. The average diameter of the left shoulder of the first three workpieces is $20.952 \mathrm{~mm}$. In contrast, the workpieces number 29 and number 30 have an average diameter of $20.925 \mathrm{~mm}$. Similar results are obtained by evaluating the right shaft shoulder. The first three workpieces have an average diameter of $20.855 \mathrm{~mm}$ and the last two workpieces have an average diameter of $20.852 \mathrm{~mm}$. Within the experiments, the roll gap width is varied in three steps and consequently the production setup is changed several times. Therefore, it is investigated, if the change of the roll gap results in a mechanical setting behaviour. In the experimental design, for example, four workpieces were produced with a set roll gap of $29 \mathrm{~mm}$ (number 23-26). The roll gap was subsequently increased to $30 \mathrm{~mm}$ for workpiece number 27 . If the measured diameters of the shafts made of C22.8 (number 4-6) are compared with the workpiece number 27 in Fig. 4, no deviation results apart from the expected production variations [5]. The difference between this workpiece and the four additional shafts of $\mathrm{C} 22.8$ is $0.07 \mathrm{~mm}$ for the left shoulder and $0.05 \mathrm{~mm}$ for the right shoulder. Thus, an influence of the mechanical setting behaviour can be excluded for the performed CWR processes.

Two types of steel are examined during the experiments. Therefore, it was investigated whether the different material properties of the two steels have a measurable effect on the manufactured geometry. However, no significant influence was determined for the two steels used, C22.8 and 41Cr4, due to their similar forming behaviour at the chosen forming temperature [25]. In summary, it is assumed that none of the three discussed process parameters within the defined process settings has a significant influence on the results of the performed study.

Figure 5 shows the results of all measured diameters for each shaft shoulder as a box plot. The previous investigation showed that the two different materials do not influence on the resulting diameters. Therefore, both materials were grouped in the subsequent analysis. In addition, the box plot takes into account the three individual measurements per shoulder instead of the mean value. The diagram shows that the variance of the produced diameters varies depending on the adjusted roll gap. If a roll gap of $30 \mathrm{~mm}$ is adjusted, the maximum manufacturing variations for the geometry of the left and right shaft shoulder are smaller than $0.12 \mathrm{~mm}$ (Fig. 5a, c). The process differs from the other two examined roll gaps due to the fact that the middle shoulder is barely deformed. Since the diameter of the semi-finished parts was also $30 \mathrm{~mm}$, only small or no deformation took place while the tools were moved towards each other. The variance of the average diameter is thus partly due to the scale caused by the initial heating. 

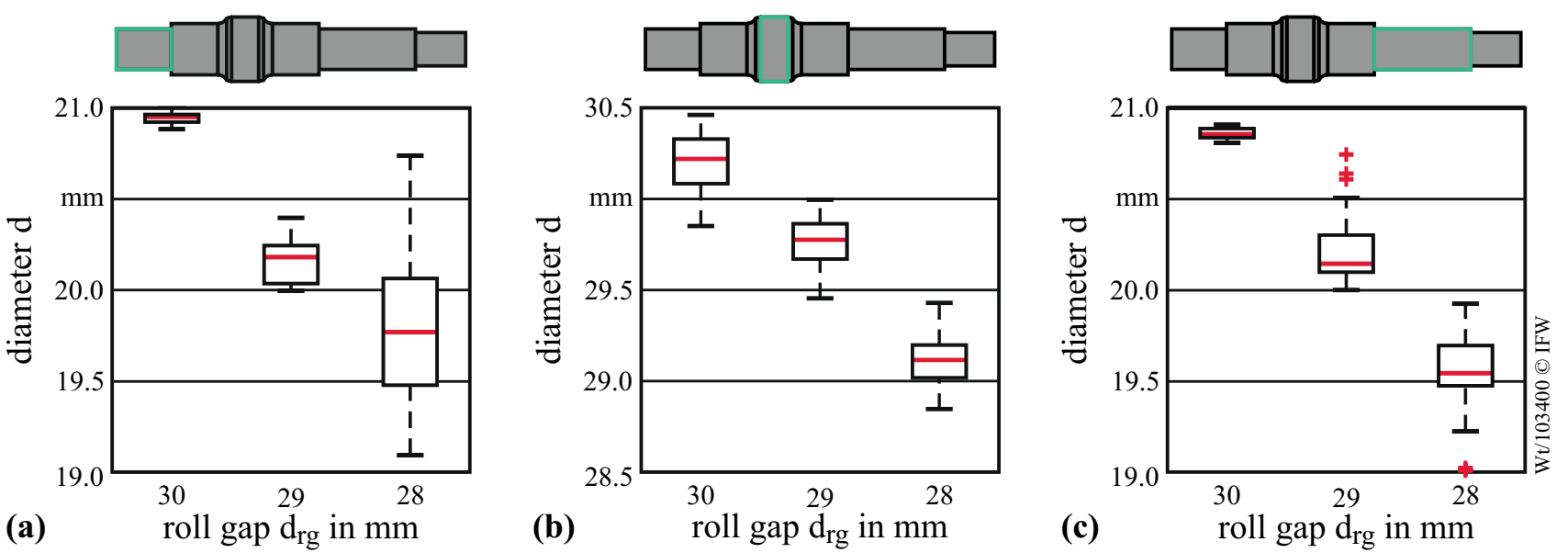

Fig. 5 Variation of diameters after cross-wedge rolling for different roll gaps and grouped for both materials

Additionally, the axial material flow towards the center of the bearing seat area and the wedge contour can result in a diameter increase $[5,6]$. The distance between the maximum and minimum diameter of the middle workpiece shoulder as well as the interquartile range is similar for the three investigated roll gaps (Fig. 5b). On average the maximum deviation for each roll gap is $0.58 \mathrm{~mm}$. The left and right shaft shoulders show different maximum deviations, if the roll gap is varied. The difference increases as the roll gap decreases. With a roll gap of $28 \mathrm{~mm}$, a maximum deviation of $0.94 \mathrm{~mm}$ between the shafts is determined for the right shoulder (Fig. 5c). At the left shoulder the maximum deviation is even $1.65 \mathrm{~mm}$, while the interquartile range is already $0.59 \mathrm{~mm}$ (Fig. 5a). The different production quality can be explained, for example, by the fact that the shafts can slip during CWR. The initial workpiece length also influences on the stability of the CWR process. Too much workpiece material will cause the ends of the part to remain undeformed by forming wedges but still will be squeezed between the tools, causing torsion within the part. This occurs more frequently with increasing compression of the shaft. This effect causes the shaft to be guided inclined between the tools, which leads to increased geometry variations. For subsequent manufacturing operations, such as machining, geometry variations represent a major challenge in terms of process safety. These variations lead to deviations in the depth of cut and to process force differences. To optimize these machining processes, it is necessary to obtain information about the workpiece geometry before manufacturing begins. Using this information, the process and evaluation can be adjusted.

\section{Feature generation}

Based on the sensors of the forming machine, the upper and lower hydraulic pressures can be measured, which occur during the horizontal movement of the tools. Since the displacement sensors showed random measurement errors, the individual measurements were synchronized by the time stamp. The hydraulic pressures for the upper tool $\mathrm{p}_{\text {up }}$ and the lower tool $p_{\text {low }}$ are depicted for the three investigated roll gaps $d_{r g}$ (Fig. 6).

A reduction of the roll gap leads to an increase in the required hydraulic pressure. By comparing the smallest and the largest investigated roll gap, the difference is up to $50 \%$ of the measured $p_{u p}$. The traversing movement of the lower tool requires a higher level of pressure. The absolute deviation between the individual roll gaps is slightly smaller for $p_{\text {low }}$.

In order to investigate, if the resulting workpiece geometry can be predicted from the measured hydraulic pressure $p$, features are extracted from the process signals. The

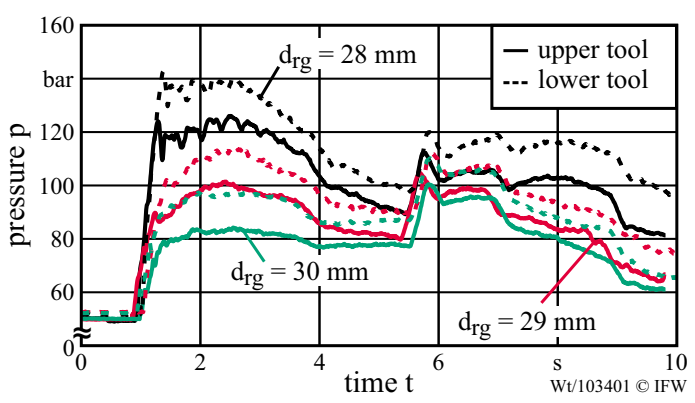

Fig. 6 Hydraulic pressures for the upper and lower tool for different roll gaps 
pressure profile was divided into two sections based on the two forming stages, depicted in Fig. 7.

The first section begins with the start of the process and ends with the start of the second forming stage. The second section includes the rest of the forming process. The maximum values of the pressure profile $p_{\max }$ and the area below the profile $p_{\text {area }}$ were determined for both tools and each section. In addition, the sum of upper and lower tools $p_{\max , \text { sum }}$ and $p_{\text {area,sum }}$ was calculated.

\section{Model-based prediction of the resulting shaft diameters}

The first step of the research was to analyse the accuracy of the prediction of the diameters of the three shaft shoulders based on meta-data (meta-based model). During the experiments, meta-data about the material used and the adjusted roll gap was available. Because the material has no significant influence at the given temperature, only the roll gap $d_{r g}$ was used for modelling. Since a quadratic correlation was identified during the analysis of the data, the quadratic roll gap $d_{r g}{ }^{2}$ was also considered in the investigations. It has been specified that each variable used in the modelling by multilinear regression must have a p-value of less than 0.05 . This means that the probability that the results of the sample are random is less than 5\%. The variables, achieved coefficients

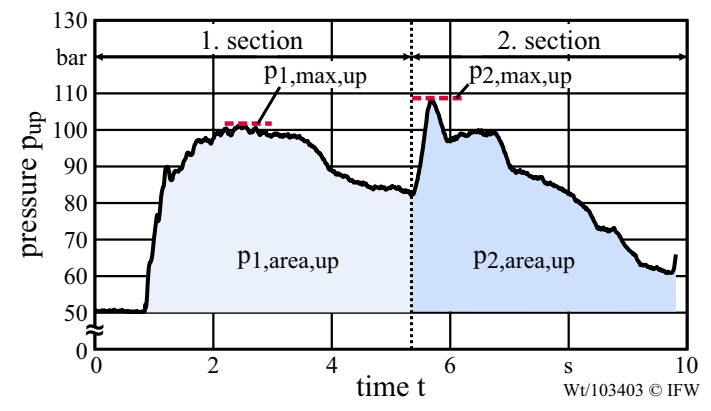

of determination $R^{2}$ and F-statistic $F$ of the individual models are presented in Table 3. The three multilinear regression models have a coefficient of determination of $R^{2}>0.91$. This enables an initial statement on the resulting shaft diameters from the information of the adjusted roll gap. However, as shown in Fig. 5 the shaft diameters differ widely even with a constant roll gap. The remaining uncertainty is of a scale that has a significant impact on subsequent machining operations. Furthermore, the modelling based on meta-data is susceptible to incorrect documentation or errors during the selection of the spacers used to adjust the roll gap within the CWR device currently used.

For this reason, the second step was to investigate, if the generated features from the hydraulic pressure can be used to achieve a higher model accuracy (feature-based model). Therefore, an individual multilinear regression model was created for each shaft shoulder to predict the diameter of the shoulder. For each model, the two input variables which lead to the highest coefficient of determination $R^{2}$ were selected. By using the sum of the first section $p_{1, \text { area,sum }}$ and the second section $p_{2, \text { area,sum }}$ as an input variable, the highest $R^{2}$ for middle and right shaft shoulder was achieved. For the model of the left shoulder, the highest $R^{2}$ was achieved based on the sum of the maximum pressures $p_{1 \text {,max,sum }}$ and $p_{2, \text { area,sum }}$. The variables and performance of the models are summarized in Table 4.

By using process signals, the adjusted coefficient of determination $R^{2}$ for the middle and right shaft shoulder was increased. The models for the left shoulder show similar results. Consequently, also the models which have only process signals as input variables are able to predict the change of the shaft diameter in case of an adjustment of the roll gap. The results for the meta-data-based model, featurebased model and the measured diameters for the left shaft shoulder are depicted in Fig. 8.

The multilinear regression model is defined according to Eq. (1). The linear relationship is represented by the constant term $\alpha$, the explanatory variable $x_{n}$ and the slope coefficients for each explanatory variable $\beta_{n}$ :

Fig. 7 Visualization of the generated features

Table 3 Information about the linear and multilinear regression models based on meta-data (meta-based model)

\begin{tabular}{llll}
\hline Variable & \multicolumn{2}{l}{ Shaft shoulder } & Right \\
\cline { 2 - 4 } & Left & Middle & $11.23 * * *(0.446)$ \\
\hline Constant & $209.09 * * *(35.19)$ & $22.00^{* * *}(0.461)$ & \\
$\mathrm{d}_{\mathrm{rg}}$ & $-1.36 \mathrm{E}+01(2.43 \mathrm{E}+00)$ & & $1.07 \mathrm{E}-02 * * *(5.26 \mathrm{E}-04)$ \\
$\mathrm{d}_{\mathrm{rg}}{ }^{2}$ & $2.43 \mathrm{E}-01 * * *(4.18 \mathrm{E}-02)$ & $9.14 \mathrm{E}-03 * * *(5.45 \mathrm{E}-04)$ & 0.943 \\
$\mathrm{R}^{2}$ & 0.957 & 0.918 & 0.941 \\
$\mathrm{Adj} . \mathrm{R}^{2}$ & 0.953 & 0.915 & \\
$\mathrm{~F}(\mathrm{df}=2 ; 27)$ & $267.80^{* * *}$ & & $413.95 * * *$ \\
$\mathrm{~F}(\mathrm{df}=1 ; 28)$ & & $288.62 * * *$ & \\
\hline
\end{tabular}

$* \mathrm{p}<0.05, * * \mathrm{p}<0.01, * * * \mathrm{p}<0.001$ 
Table 4 Information about the multilinear regression models based on process signals (feature-based model)

\begin{tabular}{|c|c|c|c|}
\hline \multirow[t]{2}{*}{ Variable } & \multicolumn{3}{|l|}{ Shaft shoulder } \\
\hline & Left & Middle & Right \\
\hline Constant & $21.45 * * *(0.238)$ & $32.42 * * *(0.210)$ & $23.02 * * *(0.268)$ \\
\hline $\mathrm{p}_{1, \text { area,sum }}$ & & $-5.33 \mathrm{E}-05^{* * *}(4.06 \mathrm{E}-06)$ & $-7.18 \mathrm{E}-05^{* * *}(5.18 \mathrm{E}-06)$ \\
\hline $\mathrm{p}_{2, \text { area,sum }}$ & $5.31 \mathrm{E}-05 * * *(5.60 \mathrm{E}-06)$ & $2.47 \mathrm{E}-05 * * *(5.65 \mathrm{E}-06)$ & $4.35 \mathrm{E}-05 * * *(7.20 \mathrm{E}-06)$ \\
\hline $\mathrm{p}_{1, \text { max,sum }}$ & $-2.56 \mathrm{E}-02 * * *(1.43 \mathrm{E}-03)$ & & \\
\hline $\mathrm{R}^{2}$ & 0.956 & 0.954 & 0.948 \\
\hline Adj. $R^{2}$ & 0.953 & 0.950 & 0.944 \\
\hline $\mathrm{F}(\mathrm{df}=2 ; 27)$ & $273.32 * * *$ & $258.11 * * *$ & $226.47 * * *$ \\
\hline
\end{tabular}

$* \mathrm{p}<0.05, * * \mathrm{p}<0.01, * * * \mathrm{p}<0.001$

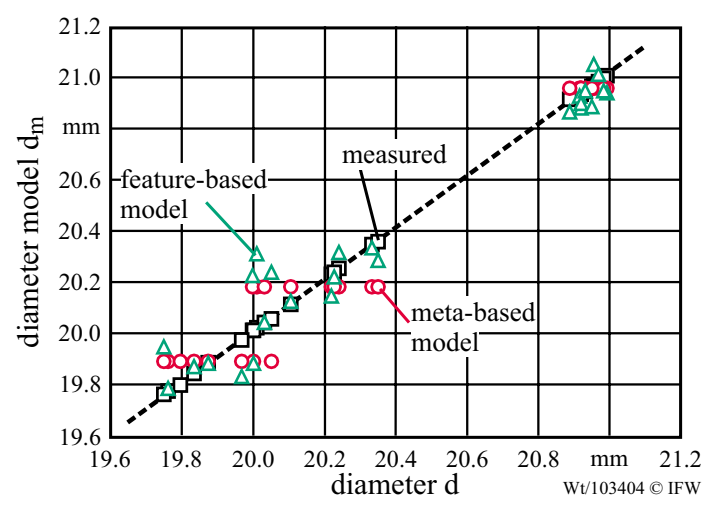

Fig. 8 Comparison of measured and modeled diameters for the left shaft shoulder

$y=\alpha+\beta_{1} x_{1}+\beta_{2} x_{2}+\cdots+\beta_{n} x_{n}$.

A variation of the allowance results in a variation of the depth of cut, which in turn correlates with the process force. Even with the high values of $R^{2}$, the predicted diameters still show significant deviations. Therefore, the distance between the upper and lower limit of the static envelopes becomes larger, if process force sensitive signals are used for evaluation. This leads to a decrease in the monitoring sensitivity.

If the assumption is made that the prediction should not differ more than $10 \%$ from the set depth of cut to achieve a sensitive process monitoring, the maximum deviation at a depth of cut of $1 \mathrm{~mm}$ should be only $100 \mu \mathrm{m}$. This value depends on the allowed percentage deviation and the set depth of cut. A general statement about the maximum permissible deviation (prediction error) is therefore not possible. Figure 9 shows the mean model deviations of the three shaft shoulders for three roll gaps and both model approaches.

For $d_{r g}=29 \mathrm{~mm}$, the feature-based model shows a lower mean deviation overall shaft shoulders. The mean deviation is $103 \mu \mathrm{m}$ compared to $129 \mu \mathrm{m}$. When evaluating the middle shaft shoulder, a higher model precision is also achieved for all investigated roll gaps. For the feature-based models,

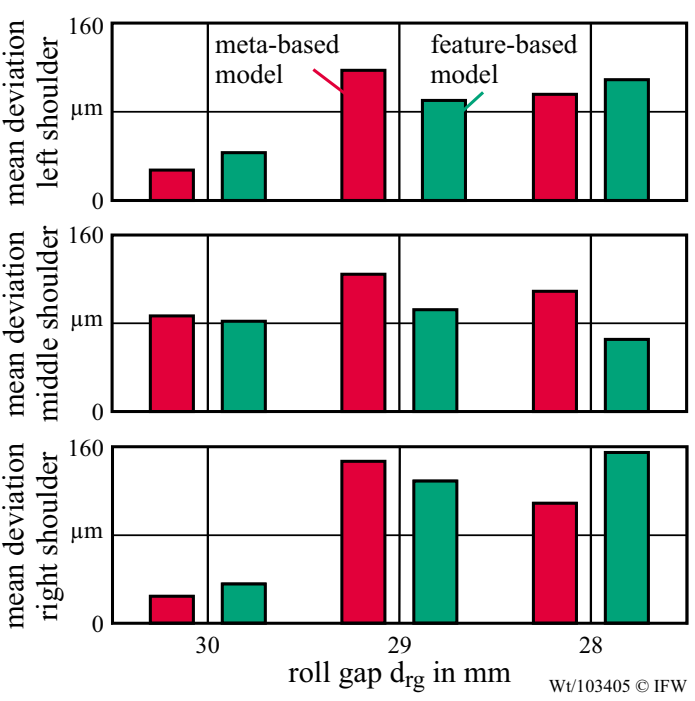

Fig. 9 Mean model error of predicted shaft shoulders diameters for different roll gaps

the average mean deviation is $80 \mu \mathrm{m}$ compared to $106 \mu \mathrm{m}$ for the meta-data-based models. For the left and right shaft shoulder, less accurate predictions are obtained, especially with $d_{r g}=28 \mathrm{~mm}$. The maximum mean deviation for the feature-based model is $154 \mu \mathrm{m}$.

The difference in modelling accuracy can be explained by disturbing effects occurring in the CWR process when the adjusted roll gap is reduced. These disturbing effects influence the measured process signals, e.g. increased friction within the test stand guiding rails due to higher forming forces. They can also be caused by the slipping of the workpiece during the forming process. In addition, the high material displacement combined with larger internal strain, due to the smaller roll gap, can also result in the appearance of the Mannesmann effect. This describes the development of material defects inside the shaft [5]. The maximum range of model error was determined for each roll gap of both models. With a roll gap of $28 \mathrm{~mm}$, this error decreases by $100-550 \mu \mathrm{m}$ for the feature-based model compared to the 
meta-based model. For the middle shaft shoulder, the error has been reduced from 530 to $460 \mu \mathrm{m}$. The error of the left shoulder of the shaft increased from 350 to $450 \mu \mathrm{m}$, if the feature-based model was used.

It can be concluded that modelling based on signals from the CWR process offers a promising approach to predict the final shaft geometry. However, the remaining model deviations based on hydraulic pressures are still high. The assumption made beforehand, that the maximum model inaccuracy at a depth of cut of $1 \mathrm{~mm}$ should not exceed $100 \mu \mathrm{m}$, is not achieved for all investigated roll gaps. This can be related to the signal quality as well as to disturbance variables that additionally influence the signals. Consequently, it is necessary to measure more signals during the process to obtain additional information that can be used for modelling. This includes advanced online temperature measurement of the tools at different locations, workpiecetool-contact pressure measurements and workpiece position surveillance.

\section{Monitoring of the Mannesmann effect}

During the CWR process, internal defects in the form of cracks and cavities can occur. These are known as the Mannesmann effect and represent a significant reduction in component safety. Since the presence of these defects cannot be detected without destruction by external visual inspection, it is being investigated, if process monitoring can be realized based on hydraulic pressures of the tools. For the evaluation, all shafts were cut open longitudinally after CWR and analysed with regard to any defects. The investigations showed that the material $41 \mathrm{Cr} 4$ is more prone to the formation of cavities compared to $\mathrm{C} 22.8$. For C22.8, material defects only occurred for $d_{r g}=28 \mathrm{~mm}$. When $41 \mathrm{Cr} 4$ was used, all shafts formed with $d_{r g}=29 \mathrm{~mm}$ also showed cavities. For a $d_{r g}=29 \mathrm{~mm}$ the inside of two shafts with different materials is depicted in Fig. 10. The curved shape of the depicted shafts can be explained by the roll gap being adjusted too small, which resulted in a defective forming process.

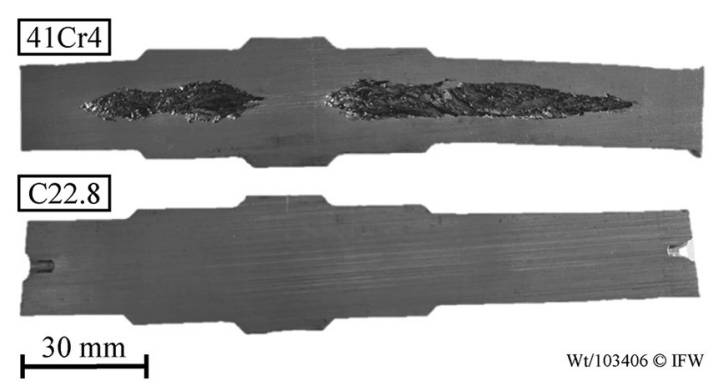

Fig. 10 Comparison of cross-wedge rolled shafts with and without material defects, both rolled at $29 \mathrm{~mm}$ roll gap
Figure 11 shows the pressure profiles of the $p_{u p}$ and $p_{\text {low }}$ for each performed measurement. For the largest roll gap of $30 \mathrm{~mm}$, the pressure profiles for both tools have high repeatability. In particular, the pressure profile of the lower tool is characterized by small deviations between the individual measurements. As the roll gap decreases, the variance between the individual pressure profiles increases. Significant deviations mainly occur in the second forming stage of the process. With a roll gap of $29 \mathrm{~mm}$, a difference between the shafts without material defect (C22.8) and with material defect (41Cr4) becomes obvious in this section. The shafts with cavities after forming show a higher pressure profile. That this effect is not mainly due to the different materials becomes clear by comparing the pressure profiles of the roll gap 30 and $28 \mathrm{~mm}$. In this case, only shafts with or without defects were formed and no material-specific separation can be determined. In addition, the only shaft produced with a roll gap of $28 \mathrm{~mm}$, which has just a small cavity of $2 \mathrm{~mm}$, has a significantly lower pressure profile in the second section. All other shafts have a material defect at this roll gap, which extends over a length of at least $50 \mathrm{~mm}$.

For the shafts formed with a roll gap of $29 \mathrm{~mm}$, the Mannesmann effect in CWR process can be determined by monitoring the hydraulic pressures. For this purpose, the signal characteristics $p_{2, \max \text {,sum }}$ and $p_{2, \text { area,sum }}$ were examined with regard to their qualification for classification. Based on both features a linear discriminant analysis (LDA) was performed and studied, if the material defects could be classified. The calculated normed features and the determined boundary are depicted in Fig. 12.

A separation of the two classes is possible with the use of an LDA for the investigated measurements. In addition

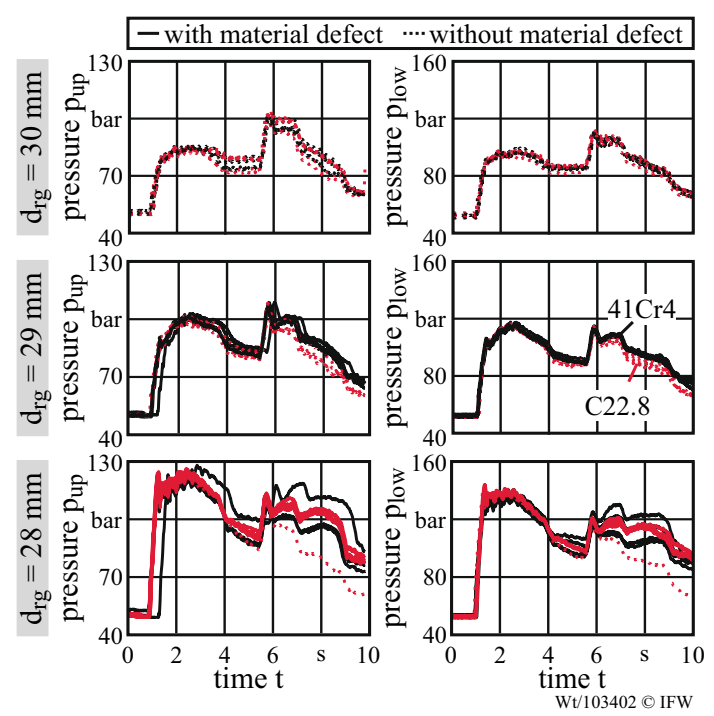

Fig. 11 Hydraulic pressures for the upper and lower tool for different roll gaps and materials 


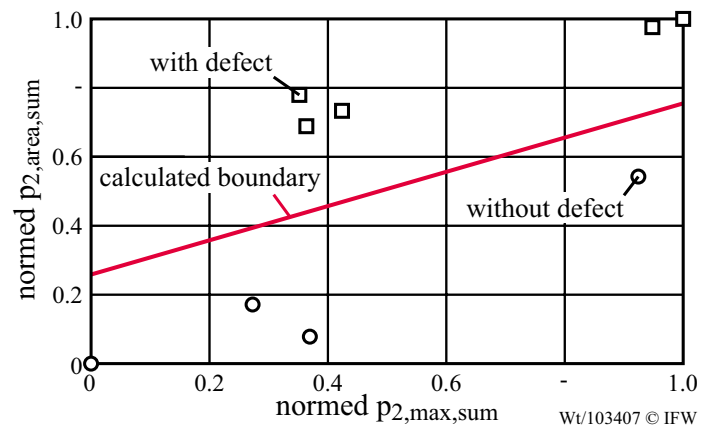

Fig. 12 Classification of material defects based on a linear discriminant analysis

to the distinct separation of all features, a significant distance remains between the boundary and each support point. Consequently, the hydraulic pressure of the tools provides a promising signal for monitoring material defects during CWR. However, due to the small number of investigated shafts, no conclusions about the sensitivity and robustness of the classification can be made at this point. This will be done with the new CWR machine in the future.

\section{Future work}

To improve the measurement accuracy of the forces, velocities and pressures during the CWR process, a new test rig is currently in construction at the IPH. The new machine also holds two sleds on which the tools are mounted. The horizontal movement of the tools is now realized by electrical motors in combination with a trapezoidal linear motion system. This results in higher positioning accuracy and easier position monitoring, since it is possible to obtain process data from the engine control system without external sensors. The width of the roll gap can either be adjusted with a trapezoidal linear motion system as well or by hydraulic actors with dual direction force capability. The first version of the CWR machine, which was used in the EU-ResearchProject "CoVaForm", had a manual height adjustment [26]. The machine currently built (2nd version) will have an electrical height adjustment, due to the demand for roll gap adjustment during rolling, as depicted in Fig. 13. The forming forces can be calculated directly from the motor momentum of the sled drive, with higher accuracy, compared to the hydraulic version used in the CWR-module.

To get more information about the state of the part itself during rolling, the new CWR tool has integrated sensors. In the current assembly state, piezoelectric sensors are used to measure the contact pressure between the part and the tool. In addition, thermocouples are used to determine the temperature close to the tool surface. At a later stage, it is planned

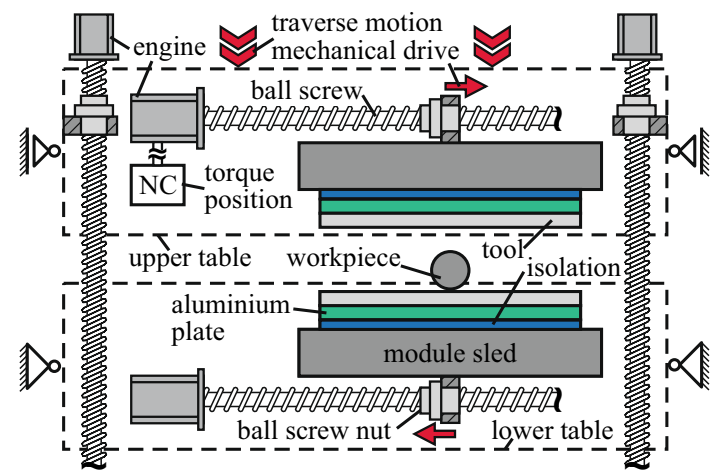

Fig. 13 Cross-wedge rolling machine at IPH (2nd version)

to measure these temperatures using thin film temperature sensors. [27]. The new CWR tool enables process-integrated measurement at critical workpiece positions. These include, for example, the temperature at the start of rolling, the temperature and contact pressure before the forming wedges and the temperature at the end of the process.

This data will be used to investigate a process monitoring system which uses information from the process chain to adjust the monitoring to the specific workpiece. In the context of CWR components, the information about the shaft diameters will be used to fit the initial geometry of a process parallel cutting simulation. Based on the calculated material removal rate, the cutting force reconstructed by structure integrated strain gauges in machine components ("feeling" machine) will be normalized (Fig. 14).

The normalized force is more robust against dimensional variations than the process force and can also be monitored using established approaches like envelope curves.

The force-sensitive components have already been installed in several machines. For example, a "feeling" lathe was developed by equipping the turret with strain gauges [28]. The suitability of this system for process monitoring has already been demonstrated [29].

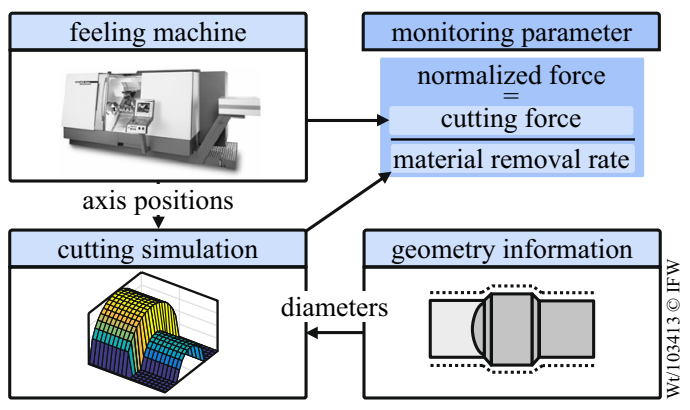

Fig. 14 Representation of a monitoring parameter for workpieces with variations in dimensions 


\section{Conclusion and outlook}

This paper presents new methods to monitor geometric workpiece variations and internal defects during CWR based on measured process information. In order to consider the dimensional variations during the monitoring of the subsequent machining process or to identify defects at an early stage, the hydraulic pressure of the tools was measured. Based on the signal features, a multilinear regression was used to predict shaft diameters for different roll gaps. Using the feature-based models, the prediction could be improved compared to meta-data-based models. The potential for classifying internal defects that occur during the forming process based on the features was also shown. However, the quality of the prediction of the workpiece geometry has to be improved, if the information will be used for the machining. For this reason, a new concept for a CWR machine was presented. The resulting component information will be used for machining to investigate process monitoring for workpieces with dimensional variations.

Acknowledgements The results presented in this paper were obtained within the Collaborative Research Center 1153 "Process chain to produce hybrid high performance components by Tailored Forming" in the subprojects B1 and B5 (252662854). The authors would like to thank the German Research Foundation (DFG) for the financial and organisational support of this project.

Funding Open Access funding enabled and organized by Projekt DEAL.

Open Access This article is licensed under a Creative Commons Attribution 4.0 International License, which permits use, sharing, adaptation, distribution and reproduction in any medium or format, as long as you give appropriate credit to the original author(s) and the source, provide a link to the Creative Commons licence, and indicate if changes were made. The images or other third party material in this article are included in the article's Creative Commons licence, unless indicated otherwise in a credit line to the material. If material is not included in the article's Creative Commons licence and your intended use is not permitted by statutory regulation or exceeds the permitted use, you will need to obtain permission directly from the copyright holder. To view a copy of this licence, visit http://creativecommons.org/licenses/by/4.0/.

\section{References}

1. Goede M, Stehlin M, Rafflenbeul L, Kopp G, Beeh E (2009) Super light car-lightweight construction thanks to a multi-material design and function integration. Eur Transp Res Rev 1(1):5-10. https://doi.org/10.1007/s12544-008-0001-2

2. Li J, Wang B, Fang S, Chen P (2020) A new process chain combining cross-wedge rolling and isothermal forging for the forming of titanium alloy turbine blades. Int J Adv Manuf Technol 108:1827-1838. https://doi.org/10.1007/s00170-020-05451-2

3. Kruse J, Jagodzinski A, Langner J, Stonis M, Behrens B-A (2020) Investigation of the joining zone displacement of cross-wedge rolled serially arranged hybrid parts. Int J Mater Form 13:577589. https://doi.org/10.1007/s12289-019-01494-3

4. Quentin L, Kruse J, Beermann R, Reinke C, Langner J et al (2019) Analysis of mapped temperature data on geometry points to characterize the influence of temperature deviations on cross-wedge rolling. AIP Conf Proc 2113:040018. https://doi. org/10.1063/1.5112552

5. Pater Z (2014) Cross-wedge rolling. In: Hashmi S, Batalha GF, van Tyne CJ, Yilbas B (eds) Comprehensive materials processing, vol 3, 1st edn. Elsevier, Amsterdam, pp 211-279. https://doi. org/10.1016/B978-0-08-096532-1.00315-0

6. Pater Z, Tomczak J, Bulzak T (2018) New forming possibilities in cross wedge rolling processes. Arch Civ Mech Eng 18:149-161. https://doi.org/10.1016/j.acme.2017.06.005

7. Pater Z, Tomczak J, Bulzak T (2020) Establishment of a new hybrid fracture criterion for cross wedge rolling. Int J Mech Sci 167:105-274. https://doi.org/10.1016/j.jimecsci.2019.105274

8. Kozhevnikova G (2012) Cross wedge rolling, 1st edn. Rue Publishing House, Minsk

9. Silva MLN, Pires GH, Button ST (2011) Damage evolution during cross wedge rolling of steel DIN 38MnSiVS5. Procedia Eng 10:752-757. https://doi.org/10.1016/j.proeng.2011.04.125

10. Çakırcalı M, Kılıçaslan C, Güden M, Kıranlı E (2013) Cross wedge rolling of a Ti6Al4V (ELI) alloy: the experimental studies and the finite element simulation of the deformation and failure. Int J Adv Manuf Technol 65:1273-1287. https://doi.org/10.1007/ s00170-012-4256-3

11. Yang C, Zhang K, Hu Z (2012) Development of central minute cavity in the workpiece of cross wedge rolling. Appl Mech Mater 215-216:766-770. https://doi.org/10.4028/www.scientifc.net/ AMM.215-216.766

12. Li Q, Lovell MR (2004) The establishment of a failure criterion in cross wedge rolling. Int J Adv Manuf Technol 24:180-189. https ://doi.org/10.1007/s00170-003-1607-0

13. Li Q, Lovell M (2008) Cross wedge rolling failure mechanisms and industrial application. Int J Adv Manuf Technol 37:265-278. https://doi.org/10.1007/s00170-007-0979-y

14. Traxler G, Baghbanpourasl A (2015) Monitoring of the cross wedge rolling process by thermography. In: Ronchi FG (ed) Proceedings of the 13th international workshop on advanced infrared technology and applications, 29 September-2 October, Pisa, Italy. Giorgio Ronchi Foundation, Italy

15. Tomczak J, Pater Z, Bulzak T (2019) A helical rolling process for producing ball studs. Arch Civ Mech Eng 19:1316-1326. https:// doi.org/10.1016/j.acme.2019.07.008

16. Pater Z, Tomczak J, Bulzak T, Wójcik Ł, Lis K (2020) Rotary compression in tool cavity-a new ductile fracture calibration test. Int J Adv Manuf Technol 106:4437-4449. https://doi.org/10.1007/ s00170-020-04943-5

17. Kim J, Huang Q, Shi J (2007) Latent variable based key process variable identification and process monitoring for forging. $\mathrm{J}$ Manuf Syst 26:53-61. https://doi.org/10.1016/j.jmsy.2007.12.001

18. Traub T, Gregório MG, Groche P (2018) A framework illustrating decision-making in operator assistance systems and its application to a roll forming process. Int J Adv Manuf Technol 97:3701-3710. https://doi.org/10.1007/s00170-018-2229-x

19. Altintas Y (1992) Prediction of cutting forces and tool breakage in milling from feed drive current measurement. J Manuf Sci Eng 114:386-392. https://doi.org/10.1115/1.2900688

20. Byrne G, Dornfeld D, Inasaki I, Ketteler G, König W et al (1995) Tool condition monitoring (TCM) - the status of research and industrial application. CIRP Ann 44(2):541-567. https://doi. org/10.1016/S0007-8506(07)60503-4

21. Teti R, Jemielniak K, O'Donnell G, Dornfeld DRA (2010) Advanced monitoring of machining operations. CIRP Ann Manuf Technol 59:717-739. https://doi.org/10.1016/j.cirp.2010.05.010 
22. Lauro CH, Brandão LC, Baldo D, Reis RA, Davim JP (2014) Monitoring and processing signal applied in machining processes-a review. Measurement 58:73-86. https://doi.org/10.1016/j.measu rement.2014.08.035

23. Denkena B, Bergmann B, Witt M (2018) Impact of hybrid components to statistical process monitoring of machining operations. Int J Adv Manuf Technol 99(1):765-771. https://doi.org/10.1007/ s00170-018-2534-4

24. Mildebrath M, Coors T, Barroi A, Pape F, Lammers M et al (2018) Herstellungsprozess und Wälzfestigkeit von hybriden hochleistungsbauteilen. Konstruktion 9:84-89

25. Behrens B-A, Bouguecha A, Bonk C, Matthias T (2017) Importance of material and friction characterisation for FE-aided process design of hybrid bevel gears. AIP Conf Proc 1896:1. https:// doi.org/10.1063/1.5008229

26. Behrens B-A, Stonis M, Blohm T, Richter J (2018) Investigating the effects of cross wedge rolling preforming operation and die forging with flash brakes on forging titanium hip implants.
Int J Mater Form 11:67-76. https://doi.org/10.1007/s1228 9-016-1329-0

27. Biehl S, Rumposch C, Paetsch N, Bräuer G, Weise D et al (2016) Multifunctional thin film sensor system as monitoring system in production. Microsyst Technol 22:1757-1765. https://doi. org/10.1007/s00542-016-2831-5

28. Bergmann B, Witt M (2020) Feeling machine for material-specific machining. Ann CIRP 69:353-356. https://doi.org/10.1016/j. cirp.2020.04.102n

29. Denkena B, Bergmann B, Witt M (2020) Feeling machine for process monitoring of turning hybrid solid components. Metals 19:903. https://doi.org/10.3390/met10070930

Publisher's Note Springer Nature remains neutral with regard to jurisdictional claims in published maps and institutional affiliations. 